\title{
Jurisdicción Especial para la Paz vs. jurisdicción ordinaria: ámbitos de competencia*
}

Recibido: 11 de octubre del 2018• Aprobado: 29 de noviembre del 2018

https://doi.org/10.22395/ojum.v17n35a12

Juan José Agudelo Posada*

\section{RESUMEN}

El presente texto tiene como objetivo demostrar las contradicciones, vacíos y ambigüedades que convergen en el tema del sistema de justicia del Acuerdo de Paz firmado entre el Gobierno de Colombia y las FARC-EP. Se hace una exposición descriptiva analítica de las disposiciones que regulan la competencia de la Jurisdicción Especial para la Paz, contenidas en el Acuerdo Final, el Acto Legislativo 01 de 2017, la Ley estatutaria que lo reglamenta y los pronunciamientos previos de la Corte Constitucional. Inicialmente se abordan problemáticas sustanciales en tres ámbitos de competencia: temporal, material y personal; y luego las dificultades procesales, en las cuales se evidencian las diferencias entre lo acordado, implementado y establecido por la Corte Constitucional.

Palabras clave: acuerdo; justicia transicional; conflicto de competencia; competencia temporal; competencia material; competencia personal; jurisdicción ordinaria.

Segundo artículo de la monografía Los conflictos de competencia entre la Jurisdicción Especial para la Paz y la Jurisdicción Ordinaria: ámbitos de competencia, para optar por el título de Magíster en Derecho de la Universidad de Medellín.

** Abogado y especialista en Derecho Administrativo, candidato a magíster en Derecho en la Universidad de Medellín. Correo electrónico: juanjoseagudeloposada18@hotmail.com Orcid: https://orcid.org/0000-0003-0834-7298 


\title{
Special Jurisdiction for Peace vs. Ordinary Jurisdiction: Competence lssues
}

\section{ABSTRACT}

The purpose of this paper is to demonstrate the contradictions, gaps and ambiguities that converge in the justice system subject of the Peace Agreement signed between the Colombian government and the FARC-EP. An analytical and descriptive exposition is made of the dispositions that regulate the competence of the Special Jurisdiction for Peace, contained in the Final Agreement, the Legislative Act 01 of 2017, the Statutory Law that regulates it and the previous pronouncements made by the Constitutional Court. Initially, substantial issues are addressed regarding three areas of competence: temporal, material and personal ones. Afterwards the procedural difficulties are exposed, in which the differences between what was agreed, implemented and established by the Constitutional Court are made evident.

Keywords: agreement; transitional justice; conflict of laws; temporary competence; material competence; personal competence; ordinary jurisdiction.

\section{Jurisdição Especial para a Paz vs. jurisdição ordinária: âmbitos de competência}

\begin{abstract}
RESUMO
O presente texto tem como objetivo demonstrar as contradições, lacunas e ambiguidades que convergem no tema do sistema de justiça do Acordo de Paz assinado entre o Governo da Colômbia e as FARC-EP. Apresenta-se uma exposição descritiva analítica das disposições que regulam a competência da Jurisdição Especial para a Paz, contidas no Acordo Final, o Ato Legislativo 01 de 2017, a Lei estatutária que o regulamenta e os pronunciamentos prévios da Corte Constitucional. Inicialmente, abordam-se problemáticas substanciais em três âmbitos de competência: temporal, material e pessoal, e, em seguida, as dificuldades processuais, nas quais são evidenciadas as diferenças entre o acordado, o implementado e o estabelecido pela Corte Constitucional.

Palavras-chave: acordo; justiça transicional; conflito de competência; competência temporal; competência material; competência pessoal; jurisdição ordinária.
\end{abstract}




\section{INTRODUCCIÓN}

El punto quinto del Acuerdo de Paz que se ocupa de la atención a las víctimas del conflicto armado interno en Colombia introdujo un sistema de justicia transicional para juzgar y sancionar a los máximos responsables de los delitos de lesa humanidad y crímenes de guerra. Vale decir que esta fue la fase más crítica alrededor de toda la negociación, su construcción tardó alrededor de dos años. El diseño de un sistema de justicia que juzgara y sancionara a los combatientes, máximos responsables de delitos de lesa humanidad y crímenes de guerra fue todo un desafío jurídico para los equipos negociadores, y a su vez, para la Corte Constitucional al momento de ejercer el respectivo control de constitucionalidad, pues ha estado bajo la mirada internacional de tribunales especializados en la protección de los derechos humanos y del Derecho Internacional Humanitario para evitar la impunidad (Redacción Judicial, 2017).

La latente desconfianza, tanto jurídica como política, conllevó que, en la redacción de los documentos finales, las partes no tuviesen un amplio margen de exactitud, concreción y seguridad jurídica, en efecto, se dio todo lo contrario. La ambigüedad, indeterminación y abstracción en la redacción de las disposiciones normativas de la justicia transicional son factores que han generado grandes problemas jurídicos relacionados con los diferentes ámbitos de competencia de los órganos judiciales, tales como la aplicación temporal, material y personal de los postulados normativos de la Jurisdicción Especial para la Paz (JEP), los cuales deben ser resueltos para el logro de los principios de justicia especial, toda vez que, de esa manera se logrará satisfacer los derechos de las víctimas, especialmente la justicia (Bernal Cuellar et al., 2016, pp. 14-15).

Las diferentes fuentes normativas del Acuerdo de Paz en el punto de justicia, como son el Acto Legislativo 01 de 2017, su ley estatutaria o código de procedimiento de la JEP (Ley 1922 de 2018 Por medio del cual se adoptan unas reglas de procedimiento para la Jurisdicción Especial para la Paz) y las sentencias emitidas sobre esas normas en virtud del control constitucional generan una gran problemática a la hora de aplicar las normas implementadas por medio de los operadores judiciales nombrados para tal fin. Surgen los conflictos de competencia internos y externos que, de una u otra manera, producen gran inseguridad jurídica. Los conflictos de competencia internos se definen como las dificultades que se suscitan entre las mismas secciones del sistema de justicia especial. Los conflictos de competencia externa son aquellas discrepancias originadas entre la JEP y la jurisdicción ordinaria, tanto de la Corte Suprema de Justicia como de la Fiscalía General de la Nación.

En ese orden, surge la pregunta: ¿cuáles son los conflictos de competencia entre la Jurisdicción Especial para la Paz y la jurisdicción ordinaria? En el presente texto se aborda dicho interrogante únicamente con relación a tres factores distribuidores 
de competencia judicial: la competencia temporal, material y personal. Se realiza una interpretación descriptiva analítica del quinto punto del Acuerdo Final, el Acto Legislativo 01 de 2017 y la Ley estatutaria del dicho Acto Legislativo, para luego esbozar unas soluciones posibles acordes con los pronunciamientos previos de la Corte Constitucional en virtud del control constitucional realizado a las diferentes normas que implementan el punto sobre la justicia en el Acuerdo de Paz.

\section{COMPETENCIA TEMPORAL DE LA JURISDICCIÓN ESPECIAL PARA LA PAZ}

El presente acápite se aborda bajo dos presupuestos: i) la duración de la Jurisdicción Especial para la Paz; y ii) la comisión en el tiempo, de delitos de lesa humanidad, crímenes de guerra y delitos comunes por los sujetos pasivos de la JEP. Frente al primero, según el Acuerdo Final y el Acto Legislativo 01 de 2017, la JEP tendrá una duración de diez años contados a partir de la entrada en funcionamiento de la totalidad de las salas y secciones y podrá tener una prórroga de cinco años más para concluir su actividad jurisdiccional, plazo que a la vez, podrá ser ampliado por cinco años más, lo que arroja un total de veinte (20) años durante los cuales la JEP podrá tener actividad judicial (OACP Final , 2016, p. 146).

Este término puede tornar muy amplio y genera grandes dificultades. Primero, al considerar los cambios políticos y sociales que se pueden presentar en el lapso de quince o veinte años; segundo, si de acuerdo con la Corte Constitucional, en la sentencia C-674 de 2017 acerca de la exequibilidad del Acto Legislativo que implementa la JEP, ese órgano judicial ha excluido a los terceros relacionados del conflicto de la competencia de la JEP y su presentación ante la misma será voluntaria, lo que generará una descongestión en el trámite de la mayoría de procesos y una celeridad en las decisiones procesales de los demás casos. Sería prudente que el tiempo de duración de la JEP fuera de unos cinco a seis años debido a que la JEP solo está instituida para conocer sobre los delitos más graves y en ese sentido, los presuntos responsables son pocos, ya que la gran mayoría de combatientes han sido beneficiados con la ley de tratamiento especial a través de la amnistía y del indulto; lo que también de una u otra manera, generaría seguridad jurídica y estabilidad institucional y se evitarían juicios rápidos que puedan menoscabar el debido proceso o juzgamientos largos que generen detrimento de los derechos de las víctimas. En ese orden, teniendo en cuenta que, dentro de ese mismo periodo de tiempo, dado el caso, se podría administrar justicia sobre los casos relacionados con el conflicto armado interno del Ejército de Liberación Nacional ELN en un futuro cercano, esto es si hubiere un proceso de paz con final exitoso con este grupo armado.

Como ejemplo de lo anterior, se encuentran algunas referencias de tribunales internacionales que administraron justicia transicional y tienen alguna similitud 
con el sistema de justicia pactado e implementado en virtud del Acuerdo Final con las FARC-EP.

El tribunal de Núremberg, adoptó un sistema de justicia transicional temporal creado en agosto de 1945 e inició sus funciones judiciales en noviembre del mismo año, encaminadas a juzgar y sancionar a los máximos responsables de delitos de lesa humanidad y crímenes de guerra cometidos durante la Segunda Guerra Mundial por algunos líderes políticos alemanes. Los Juicios de Núremberg tuvieron una duración de un año de ejercicio de funciones judiciales. En total, juzgó y sancionó a 13 responsables de los delitos antes mencionados (Comisión Preparatoria de la Corte Penal Internacional, 2002, p. 18).

Así mismo, el tribunal híbrido y especial de justicia para Sierra Leona adoptó un sistema de justicia transicional creado en enero del 2002 entre la Organización de las Naciones Unidas y la República de Sierra Leona para el juzgamiento de los delitos de lesa humanidad y crímenes de guerra, ocurridos durante la guerra civil de ese país. Tuvo una duración de diez años y emitió su última sentencia en firme en el 2013, con altos índices de seguridad jurídica e imperio de la ley (ICTJ, s.f., p. 1).

En el mismo sentido, el tribunal internacional creado para el juzgamiento de crímenes atroces: genocidio, crímenes de guerra y de lesa humanidad, cometidos durante el sangriento conflicto armado interno en Ruanda, creado el 8 de noviembre de 1994, tuvo una duración de un año exacto y pudo garantizar y reconocer derechos de las innumerables victimas (Resolución 955 de 1994, artículo 7).

Vale decir entonces que la amplia duración de la JEP no necesariamente significa que se vaya administrar mejor justicia o que de esa manera se garantizarán y reivindicarán los derechos de las víctimas, sino que, con una reducción temporal de las funciones del sistema de justicia especial, también se podrían obtener resultados satisfactorios para cada víctima del conflicto armado interno y se garantizarían derechos fundamentales en la defensa de los presuntos responsables de los delitos que son competencia de ese tribunal especial. Los ejemplos citados demuestran de manera directa que se puede administrar justicia transitoria y autónoma en tiempos cortos con altos estándares de justicia.

Respecto al segundo presupuesto, uno de los factores que determinan la competencia de las distintas jurisdicciones es el factor temporal y esto conlleva delimitar exactamente, el tiempo a partir del cual alguna corporación judicial tiene la aptitud constitucional y legal para conocer y decidir sobre algún asunto puesto a su conocimiento para que se tome una decisión de fondo.

Si se toma como referencia el Acuerdo Final, se estipuló en el punto quinto sobre justicia, relativo a la competencia temporal de la Jurisdicción Especial para la Paz, que dicho sistema de juzgamiento conocerá de los asuntos graves, esto es, delitos de lesa humanidad y crímenes de 
guerra que sucedieron con anterioridad a la entrada en vigor del mismo acuerdo (OACP, 2016, p. 145). Inmediatamente, ese enunciado remite al Acto Legislativo para la paz (Congreso de Colombia, 2016), el cual en su artículo 5 estableció:

\begin{abstract}
Artículo 5. Vigencia. El presente Acto Legislativo rige a partir de la refrendación popular del Acuerdo Final para la terminación del conflicto y la construcción de una paz estable y duradera.
\end{abstract}

De acuerdo con el artículo citado, la refrendación popular se efectuó por medio del Congreso de la República el $1^{\circ}$ de diciembre del 2016, lo que obligó al presidente de la República realizar la implementación normativa del Acuerdo Final, en lo que a su competencia le corresponde, de la mano del Congreso de la República en lo que es de su marco funcional.

Lo que vale resaltar de la mencionada fecha es que la Jurisdicción Especial para la Paz es competente para conocer de manera prevalente, preferente y autónoma de todos los delitos de lesa humanidad y crímenes de guerra cometidos que tengan relación directa e indirecta con el conflicto armado y que hayan tenido lugar hasta el $1^{\circ}$ de diciembre del 2016. Esta norma es contraria a la regla del derecho penal según la cual las normas tienen aplicación después de expedidas, mientras que el Acuerdo Final y las normas implementadas en el punto de justicia tienen aplicación hacia el pasado, figura propia del cambio político fruto de la transición.
En este punto, vale mencionar que tanto el Acuerdo Final como el Acto Legislativo 01 de 2017 en su artículo 5, establecieron que quien cometiera un delito luego de la fecha indicada, no perdía ipso facto los beneficios de la justicia transicional, sino que, podría seguir gozando de otros beneficios judiciales especiales, en otros términos. El asunto se corrigió según sentencia de la Corte Constitucional sobre el control constitucional realizado al Acto Legislativo 01 de 2017 y se estableció, que quien incumpla lo acordado y cometa algún delito después del 01 de diciembre de 2016, será juzgado por la jurisdicción ordinaria.

A nuestro parecer, la solución no corrige estrictamente la contradicción normativa en el supuesto de que, frente a ex combatientes que no son beneficiarios de amnistía e indulto y que cometan delitos luego de la refrendación del Acuerdo Final, sigue la competencia irrogada de la sala de definición de situaciones jurídicas, ya que esta es competente para conocer y definir la situación jurídica de todos los que hayan accedido al componente de esa justicia (OACP, 2016).

Adicionalmente, el Acto legislativo 01 de 2017, en su capítulo III, artículo transitorio 5, tercer párrafo, establece:

Si con posterioridad a la entrada en vigencia de este Acto Legislativo y a la finalización del proceso de dejación de armas alguna de las personas sujetas a la jurisdicción de la JEP cometiera un nuevo delito, éste [sic] será de conocimiento de la justicia ordi- 
naria. Adicionalmente, en esos casos la JEP evaluará si esta nueva conducta, cuando corresponda con las que serían de su competencia, implica un incumplimiento de las condiciones del Sistema, que amerite no aplicarle las sanciones propias o alternativas a las que tendría derecho por los delitos de competencia de la JEP, sino las ordinarias contempladas en la misma JEP, que deberán ser cumplidas en los sitios ordinarios de reclusión. (Congreso de Colombia, 2017)

Como ejemplo de lo anterior, se ha presentado el caso concreto del miembro directivo del partido político FARC, alias "Jesús Santrich", capturado en el mes de abril del 2018 (Fiscalía General de la Nación, 2018), acusado de narcotráfico y relación con carteles delincuenciales extranjeros. Este caso creó un limbo jurídico por la misma competencia que la JEP tiene sobre este, específicamente la sala de definición de situaciones jurídicas, la cual se debe limitar a verificar, de acuerdo a los elementos materiales probatorios, que la conducta tuvo lugar posterior al $1^{\circ}$ de diciembre de 2016 para así trasladarlo a la jurisdicción ordinaria y no definir la situación jurídica en estricta medida del capturado, pues no tendría sentido interpretativo que quien siga cometiendo delitos no relacionados directa ni indirectamente con el conflicto armado interno, y después de la firma y refrendación del Acuerdo Final, siga siendo sujeto del sistema de justicia transicional; esto sin perjuicio de las declaraciones o confesiones que pueda rendir ante la comisión de la verdad, órgano extrajudicial que compone el Sistema Integral de Verdad, Justicia, Reparación y no Repetición.

Especial análisis merece la parte del enunciado normativo relacionado con la aplicación de las sanciones ordinarias de la misma JEP a quienes hayan cometido delitos luego del $1^{\circ}$ de diciembre del 2016, según el sentido literal, la JEP nunca perdería competencia en casos de reincidencia, pues esta es competente para aplicar sanciones ordinarias y no las especiales a aquellos agentes que incumplan con lo pactado. Esa parte del texto la debe aclarar la Corte Constitucional y establecer que quien reincida luego de la fecha de entrada en vigor del Acuerdo Final, automáticamente perderá todos los beneficios de la justicia transicional. Realizar esa concreción evitará nuevas crisis interpretativas en casos de reincidencia en el futuro.

Así las cosas, la conducta a seguir para la solución del caso citado es que la Fiscalía General de la Nación remita las pruebas a la sala de definición de situación jurídica o en su defecto a la sección de revisión del Tribual de Paz y simultáneamente a la sala penal de la Corte Suprema de Justicia. Las primeras se deberán limitar a la verificación de la fecha de la perpetración del delito por el que fue capturado y dado el caso de que efectivamente se haya dado de forma posterior a la firma del Acuerdo y se pueda probar, se deberá remitir la providencia judicial a la jurisdicción ordinaria.

Otro asunto en el caso en mención es la solicitud de extradición que pesa sobre 
el capturado. Frente a este punto en específico, el Acuerdo Final establece la posibilidad de que los guerrilleros desmovilizados puedan ser extraditados por delitos como aquel de narcotráfico (OACP, 2016, p. 170). Esa posibilidad es una premisa facultativa, pues el mismo texto no establece la obligación real de extradición y entraría una ponderación entre los derechos de las víctimas a saber la verdad sobre homicidios, desapariciones forzadas, reclutamiento de menores para el conflicto armado y otros delitos cometidos con ocasión del conflicto armado y el castigo por parte de otro Estado por delitos como el narcotráfico. Esta dicotomía la deben resolver tanto la sala penal de la Corte Suprema de Justicia como el presidente de la República (Uprimny, 2018).

\section{COMPETENCIA MATERIAL DE LA JURISDICCIÓN ESPECIAL PARA LA PAZ}

Para dar inicio a este acápite, cabe afirmar que la Jurisdicción Especial para la Paz se encarga de juzgar y sancionar los delitos que no son amnistiables ni indultables a la luz del Acuerdo Final y del Acto Legislativo 01 de 2017. Así las cosas, surge la siguiente pregunta: ¿cuáles son los delitos que conocerá la Jurisdicción Especial para la Paz?

En virtud del Acuerdo Final, la justicia especial para la paz se encarga de juzgar y sancionar los delitos de lesa humanidad, genocidio, crímenes de guerra, toma de rehenes u otra privación grave de la libertad, tortura, ejecuciones extrajudiciales, desaparición forzada, sustracción de menores de edad, acceso carnal violento y otras formas de violencia sexual, desplazamiento forzado. Todos estos delitos enumerados serán objeto de competencia de la JEP, conforme a los criterios de selección y priorización consagrados en el Acto Legislativo 01 de 2012 (congreso de la República, 2012), el denominado marco jurídico para la paz.

El cimiento para la clasificación de las conductas punibles objeto de la JEP son las diferentes normas relativas al Derecho Internacional de los Derechos Humanos (DIDH) y el Derecho Internacional Humanitario (DIH). En ese sentido, establece el Acuerdo Final que:

\begin{abstract}
Las diferentes secciones del tribunal de paz y la sala de investigación y acusación, al adoptar sus resoluciones o sentencias harán una calificación jurídica propia del sistema respecto de las conductas objeto del mismo, calificación que se basará en el código penal colombiano y/o en las normas de derecho internacional en materia de derechos humanos, derecho internacional humanitario o derecho penal internacional, siempre con aplicación del principio de favorabilidad (OACP, 2016).
\end{abstract}

Hasta ahí no se da ninguna dificultad normativa. Pero, en virtud del conflicto armado, el grupo guerrillero desmovilizado y reinsertado hizo uso de una conducta sistemática que genera grandes desafíos normativos para la aplicación de una sanción proporcional a lo cometido. 
En primer momento, el grupo guerrillero practicó el narcotráfico de manera organizada como forma de financiamiento y de lucro para la lucha armada, al tanto de convertirse en uno de los carteles de droga más grande a nivel mundial (Acosta, 2016). Es por esto que este delito en específico, es el que ha conllevado, además de una gran controversia política, también un desafío jurídico sustancial para la implementación del Acuerdo Final y la administración de justicia; en vista también de que narcotraficantes comprobados han querido ingresar al sistema de justicia especial, so pretexto de que el tráfico ilegal de drogas es conexo al desarrollo del conflicto armado interno (Corte Suprema de Justicia, 2018).

Frente a ese delito relacionado con el conflicto armado interno, se ha suscitado una gran controversia en relación con la aplicación de una justicia efectiva y la reivindicación de los derechos de las víctimas, al punto de acudir a tribunales internacionales.

En ese orden, vale hacer varias precisiones: el Acuerdo Final no dispuso exactamente cuál es la jurisdicción con competencia para conocer los delitos de ejecución permanente como el narcotráfico. Seguidamente, el Acto Legislativo 01 de 2017 estableció que la misma ley estatutaria reglamentaría en qué casos y bajo qué circunstancias corresponde a la jurisdicción ordinaria la investigación y juzgamiento de los delitos contenidos en el artículo 375 de la Ley 599 de 2000¹.

"Artículo 375. Conservación o financiación de plantaciones. El que sin permiso de autoridad competente
Seguidamente, la ley estatutaria, que reglamenta el Acto Legislativo 01 de 2017, en su artículo 62, numeral 3 establece lo siguiente:
La jurisdicción ordinaria tendrá competencia respecto de cual- quiera de las conductas referidas, cuya comisión haya iniciado antes del 1 de diciembre de 2016, cuando se hayan realizado actos de ejecución después de dicha fecha. (Congreso de Colombia, 2017)

Aunado a ello, según lo indicado por la Corte Constitucional en la sentencia C-080 de 2018 sobre el control constitucional de la ley estatutaria de la JEP, la citada norma fue declarada inconstitucional, anotando que:
Tratándose de los referidos deli- tos de narcotráfico de ejecución permanente, corresponde a la JEP en ejercicio de su competencia prevalente, evaluar la conducta y determinar su remisión a la jurisdicción ordinaria. (Corte Constitucional, 2018, p. 12)

Es importante citar ese extracto del comunicado de la Corte Constitucional sobre la ley estatutaria del Acto Legislativo 01 de 2017 puesto que, según la sentencia C- 674 de 2017, la Corte Constitucional sostuvo que las conductas de narcotráfico de ejecución permanente 
que se cometan, se deben someter a la jurisdicción ordinaria.

Así las cosas, una incertidumbre jurídica real concerniente a la investigación, juzgamiento y sanción de la conducta del narcotráfico relacionado con el conflicto armado interno generará profundos conflictos de competencia y haciendo más extensivo el problema, será una tarea difícil en la práctica para perseguir a ex guerrilleros reincidentes que siguen con los cultivos ilícitos, ya que seguirían delinquiendo y sin dejar de ser sujetos titulares de derechos de la justicia transicional (Fiscalía General de la Nación, 2018a).

El caso de alias Jesús Santrich, a la luz de las diferentes sentencias de la Corte Constitucional, del Acto Legislativo 01 de $2017^{2}$ y el pronunciamiento previo sobre

"Artículo Transitorio 23. Competencia de la Jurisdicción Especial para la Paz.

La Jurisdicción Especial para la Paz tendrá competencia sobre delitos cometidos por causa, con ocasión, o en relación directa o indirecta con el conflicto armado y sin ánimo de obtener enriquecimiento personal ilícito, o en caso de que existiera, sin ser este la causa determinante de la conducta delictiva. Para tal efecto se tendrán en cuenta los siguientes criterios:

a. Que el conflicto armado haya sido la causa directa o indirecta de la comisión de la conducta punible o,

b. Que la existencia del conflicto armado haya influido en el autor, partícipe o encubridor de la conducta punible cometida por causa, con ocasión o en relación directa o indirecta con el conflicto armado en cuanto a:

- Su capacidad para cometerla, es decir, a que por razón del conflicto armado el perpetrador haya adquirido habilidades mayores que le sirvieron para ejecutar la conducta

- Su decisión para cometerla, es decir, a la resolución o disposición del individuo para cometerla. el control constitucional realizado a la ley estatutaria reglamentaria del mismo, resultan insuficientes, esos insumos normativos para resolver tal caso concreto.

En ese orden de ideas, se debe realizar un análisis mancomunado entre la jurisdicción ordinaria y la JEP, teniendo en cuenta las siguientes connotaciones fácticas, la intención del autor y la destinación del dinero producto de las transacciones delincuenciales, para así determinar la calificación jurídica para que el narcotráfico sea considerado delito conexo al delito político: i) participación activa del grupo exguerrillero FARC-EP en el cobro por la cantidad de cultivos ilícitos que produzca otro grupo armado al margen de la ley (impuesto al gramaje) y/o seguridad de los cultivos, campamentos y laboratorios; ii) uso del narcotráfico para sobrevivencia rudimentaria; y iii) si la producción y comercialización de sustancias ilícitas se realizó en virtud de un cartel organizado para el tráfico de drogas.

Para el primer y tercer supuesto, si son conductas cometidas con posterioridad al $1^{\circ}$ de diciembre de 2016, la jurisdicción competente para conocer exclusivamente del mismo, sería la ordinaria, por ende, la Fiscalía General de la Nación, asumiría la competencia para la investigación y

- La manera en que fue cometida, es decir, a que, producto del conflicto armado, el perpetrador de la conducta haya tenido la oportunidad de contar con medios que le sirvieron para consumarla.

- La selección del objetivo que se proponía alcanzar con la comisión del delito." (Congreso de Colombia, 2017) 
acusación ante cualquier juez penal de la república.

Si se actúa en virtud del segundo supuesto, en el cual, el cultivo y comercialización de los cultivos ilícitos se realiza con el fin de sobrevivir en la selva y mantener la lucha armada en contra del orden constitucional, el delito se debe considerar como un delito conexo a la variedad de conductas punibles y debe ser competencia plena de la JEP.

\section{COMPETENCIA PERSONAL DE LA JURISDICCIÓN ESPECIAL PARA LA PAZ}

La Jurisdicción Especial para la Paz se aplicará de forma diferenciada a todos quienes, habiendo participado de manera directa o indirecta en el conflicto armado, cometieron delitos en el contexto y en razón de este, siempre que cumplan con las condiciones del Sistema Integral de Verdad, Justicia, Reparación y no Repetición (OACP, 2016). La JEP fue diseñada e implementada para la investigación, acusación, juzgamiento y sanción de los máximos responsables de delitos de lesa humanidad, cometidos directa e indirectamente durante y con ocasión del conflicto armado interno (Congreso de Colombia, 2017).

Inicialmente, el Acuerdo Final contempló la posibilidad de que algunos civiles fueran obligados a comparecer a la JEP. El Acto Legislativo 01 de $2017^{33}$, determinó

\footnotetext{
3 "Artículo 16. Competencia sobre terceros. Las personas que, sin formar parte de las organizaciones o grupos armados, hubieren contribuido de manera directa o indirecta a la comisión de
}

la obligación, pero también la opción voluntaria de acudir a esa justicia. La Corte Constitucional, mediante sentencia C-674 de 2017, estableció que la comparecencia de los terceros a la JEP será de manera voluntaria, mas no obligatoria. Fundamentó su decisión en dos aspectos: i) el acceso forzoso de los no combatientes en el conflicto armado a la JEP y al tratamiento especial correspondiente anula la garantía del juez natural y el principio de legalidad; ii) el régimen punitivo al que se encuentran sometidos los terceros civiles que acceden a la JEP no está tipificado en el Acto Legislativo y en esa medida, algunos aspectos son distintos y eventualmente más desventajosos que el escenario previsto para los combatientes en el conflicto.

De los dos argumentos dados por la Corte Constitucional, solo es aceptable el segundo y de manera parcial, puesto que en los procesos de transición es posible crear diferentes mecanismos de justicia y de sanción alternativa para que todos los participantes en el conflicto armado cumplan de manera eficaz con uno de los puntos estructurales del sistema integral de justicia. Es decir que se pueden diseñar, bajo estándares del DIH y DIDH,

delitos en el marco del conflicto, podrán, acogerse a la JEP y recibir el tratamiento especial que las normas determinen, siempre que cumplan con las condiciones establecidas de contribución a la verdad, reparación y no repetición.

Lo anterior, sin perjuicio de las competencias de la Sala de Reconocimiento de Verdad y Responsabilidad y de la sección de Revisión del Tribunal para la Paz, respecto de la comparecencia de aquellos terceros que hubieran tenido una participación activa o determinante en la comisión de los siguientes delitos [...] (Congreso de Colombia, 2017). 
sanciones especiales en virtud de todo el proceso transicional para los terceros que han cometido delitos de lesa humanidad con ocasión del conflicto armado.

Con base en lo anterior, también se ha creado una dificultad normativa en el sentido en que existen personas que presuntamente han cometido delitos de lesa humanidad, pero que no tuvieron relación directa o indirecta con el conflicto armado y han acudido a la JEP, lo cual vulnera la acción penal de la Fiscalía General de la Nación. Hay también otros casos concretos en los cuales los sujetos implicados en delitos comunes deciden solicitar acogerse a la justicia especial so pretexto de la existencia del conflicto armado en el tiempo de la comisión del delito.

Puntualmente, los delitos que presunta o que realmente cometieron agentes estatales, relacionados con grupos paramilitares, han sufrido contradicciones normativas al ser rechazados por la JEP. Exactamente, se mencionan dos tipos de casos: i) excongresistas que durante su periodo como legisladores cometieron delitos relacionados directa o indirectamente con el conflicto armado al financiar a grupos paramilitares ${ }^{4}$; y ii) exministros que pertenecieron a un gobierno que dentro de su plan antisubversivo, implementó medidas radicales de choque en contra de la rebelión y que fueron condenados por otros delitos comunes ${ }^{5}$.

\footnotetext{
Se hace referencia a los casos de los ex congresistas Álvaro Ashton y David Char, procesados por parapolítica (JEP, 2018b).

Se hace referencia a los casos de los exministros Diego
}

Frente al primer supuesto, en un primer momento la JEP rechazó (resoluciones 083 y 084 de la Sala de Definición de Situación Jurídica) la solicitud de los dos excongresistas con el argumento de que los delitos imputados no estaban relacionados directa o indirectamente con el conflicto armado interno (JEP , 2018a).

Lo anterior fue un equívoco, toda vez que en el delito de concierto para delinquir por el nexo de los imputados con grupos paramilitares sí es una conducta punible relacionada con el conflicto armado, en el sentido de que el paramilitarismo jugó un papel protagónico en todo el desarrollo contrainsurgente en Colombia, por ende, un sujeto activo del conflicto armado (Cruz Rodríguez, 2007).

Vale decir que la competencia personal de la JEP debe ser amplia y que su interpretación se encuentre armonizada con el Acuerdo Final, partiendo de que debe existir una unidad y coherencia teleológica en las diferentes normas sobre justicia que implementaron el Acuerdo Final.

De manera acertada y a través de la sección de apelación del tribunal de la JEP, luego de un recurso de apelación instaurado por los dos excongresistas, esta decidió acogerlos condicionadamente, con base en que el juzgamiento de agentes del Estado y de terceros civiles que aportaron a la existencia y prolongación del conflicto armado es necesario para esclarecer la verdad, superar el conflicto y

Palacio, Alberto Velásquez y Sabas Pretelt, procesados y condenados por delitos contra la administración pública (Semana, 2017). 
dignificar a las víctimas, todo ello enmarcado dentro de los principios fundantes del Sistema Integral de Verdad, Justicia, Reparación y no Repetición (Tribunal para la Paz, 2018a).

Pero, respecto a la comisión de otros delitos en los cuales la intención en la comisión del delito y el bien jurídico tutelado son diferentes y por ello no son competencia de la JEP sino de la justicia ordinaria, resulta un problema jurídico a resolverse de manera clara, se deben tener en cuenta los siguientes elementos: relación del delito con el conflicto armado interno y el beneficio personal con la comisión del delito.

Si se está en presencia de un delito en contra de la administración pública o alguna otra conducta punible que atente contra un bien jurídico tutelado, diferente al orden constitucional, será competencia de la jurisdicción ordinaria. Con respecto al segundo elemento: el beneficio personal que le trae, éste complementará la teoría de cada caso para calificar la conducta y por ende la jurisdicción competente.

Frente al segundo postulado, la JEP ha actuado en concordancia con lo planteado en el Acuerdo Final y el Acto Legislativo 01 de 2017. De forma consecuente, los exministros condenados por delitos comunes pueden ser sujetos voluntarios de la JEP, únicamente si aportan verdad sobre lo ocurrido, en razón a que, a pesar de que la competencia personal de la JEP debe interpretarse extensivamente, tampoco puede desviar los fundamentos jurídicos, políticos y sociales por los cuales fue creada la justicia especial.

\section{CONCLUSIONES}

En los diferentes escenarios normativos planteados anteriormente, resultan evidentes las divergencias entre lo acordado, lo implementado y lo establecido por la Corte Constitucional en sus pronunciamientos frente al sistema de justicia transicional. Un claro ejemplo de ello es lo pactado en el Acuerdo Final frente a la solución de los conflictos de competencias entre la JEP y la jurisdicción ordinaria, el cual dispuso lo siguiente:

En el supuesto de existir con-
flicto de competencia entre
cualquier jurisdicción y la
Jurisdicción Especial para la
Paz, resolverá dicho conflicto
una Sala Incidental conformada
por 3 magistrados del Consejo
Superior de la Judicatura, ele-
gidos por éste [sic] y 3 magis-
trados de las Salas o Secciones
de la Jurisdicción Especial para
la Paz no afectadas por dicho
conflicto jurisdiccional, elegidos
por la plenaria de la Jurisdicción
Especial para la Paz. La decisión
se adoptará en la sala incidental
por mayoría simple y en caso
de no alcanzarse una mayo-
ría, en aplicación del carácter
preferente de la Jurisdicción
Especial para la Paz, resolverá el
presidente de estla] Jurisdicción
(OACP, 2016, p. 145).

Y seguidamente, el Acto Legislativo 01 de 2017, en su artículo 9 dispuso lo siguiente: 
Los conflictos de competencia entre cualquier jurisdicción y la JEP serán dirimidos por una sala incidental conformada por 3 magistrados de la Corte Constitucional elegidos por esta y 3 magistrados de las salas o secciones de la JEP no afectadas por dicho conflicto jurisdiccional. Estos últimos serán elegidos por la plenaria de la JEP. La decisión se adoptará en la sala incidental por mayoría simple y en caso de no alcanzarse una mayoría, en aplicación del carácter preferente de la Jurisdicción Especial para la Paz, resolverá el presidente de esta Jurisdicción. (Congreso de Colombia, 2017

Necesariamente, los diferentes ámbitos de competencia mencionados, necesitan de una concreción normativa que permita hacer una interpretación y aplicación acertada en dirección a la garantía de los derechos fundamentales y de los principios de la justicia especial. En ese sentido, el ejercicio de la competencia por parte de la JEP debe ser de manera amplia, generosa y evitar colocar restricciones a aquellos sujetos que hipotéticamente han cometido delitos graves de lesa humanidad relacionados directa o indirectamente con el conflicto armado interno y que quieren comparecer ante dicho órgano judicial.

Vale mencionar lo que estudió la Corporación Derecho, Justicia y Sociedad, Dejusticia, al respecto:

La competencia de la JEP debe ser interpretada ampliamente, e incluso es razonable entender que estaría amparada en una presunción según la cual toda duda sobre su competencia en un caso, conducta, o persona, debería ser resuelta a su favor (indubio pro JEP). Esta interpretación es coherente con el propósito de que la JEP sea en realidad una instancia de cierre judicial al conflicto armado. (Dejusticia, 2018)

En esa dirección, la JEP en sus diferentes salas debe adoptar una regla de procedimiento interno en cuanto a la competencia, consistente en determinar la intención con la cual fue cometido el delito que se imputa a cada persona que pretende ser sujeto voluntario de la JEP, ya que la comisión de conductas relacionadas y de otros delitos no relacionados con el conflicto armado puede seguir generando tensiones entre la jurisdicción ordinaria y la JEP, por la intermitente desconexión que pueden tener los unos con los otros; esto es, personas que tienen alguna imputación de delitos relacionados con el conflicto armado interno, como el concierto para delinquir, pero que en el misma imputación tienen otras conductas punibles como el cohecho, tráfico de influencias, narcotráfico de manera organizada, que en nada tienen que ver con la ocurrencia del conflicto armado interno.

Para ello, se propone que esos terceros con imputación de delitos relacionados acudan voluntariamente a la JEP y a la comisión de la verdad, asuman los respectivos compromisos judiciales y extrajudiciales. En este punto, la Corte Constitucional debe propender dejar por sentado en el procedimiento 
contemplado para la JEP, que aquellas conductas no relacionadas ni directa o indirectamente con el conflicto, una vez los sujetos asuman las responsabilidades y compromisos en la JEP, acudan a la jurisdicción ordinaria y respondan por los demás delitos, de los cuales la JEP no es competente para su investigación, judicialización y sanción.

En el orden de ideas sugerido anteriormente, se evitaría de cierta manera algún margen de impunidad y se cumpliría tanto con los postulados democráticos del Estado, como con los ejes centrales del Acuerdo de Paz y del cambio político propio de la transición.

De otra parte, vale afirmar que la concretización de las diferentes normas y principios, a la luz del funcionamiento de la JEP, comprende una conceptualización progresista del derecho como instrumento transformador de la sociedad que por décadas ha sufrido la barbarie y la atrocidad. Según ello, se predica lo siguiente:

\begin{abstract}
El derecho desempeña un papel explícitamente constructivo y ritualizado estructurando los cambios interpretativos que se perciben como transición política mesurada en pro de la integración (Teitel, 2017).
\end{abstract}

La debida y eficaz administración de justicia transicional debe propender por la garantía de los postulados básicos del Estado Social de Derecho. Las diferentes normas que regulan la competencia judicial son tan importantes como el acuerdo mismo y es en base a ello que la determinación, delimitación y taxatividad de esas normas conlleva la consecución de los fines para los cuales fue diseñada, creada e implementada la Jurisdicción Especial para la Paz.

La reiterada jurisprudencia de la Corte Constitucional y de otros cuerpos judiciales de protección de derechos humanos se han mostrado afines al establecer que las normas externas e internas delimitantes de la competencia temporal, material y personal deben ser claras, precisas y acordes con los postulados elementales del Acuerdo Final y de la ley estatutaria de la JEP.

\section{REFERENCIAS}

Acosta, L. J. (2016, abril 16). Entrevista-FARC siguen involucradas en narcotráfico pese a negociación de paz: Policía de Colombia. Reuters. Recuperado de https://lta.reuters. com/articulo/drogas-colombia-guerrillaidLTAKCN0X92L5

Bernal Cuellar, J., Ramelli Arteaga, A., Parra Quijano, J., Sierra Porto, H. A., Andrade Castro, J. A., Caldas Botero, L. F., y Zambrano Salazar, L. F. (2016). Reflexiones jurídicas sobre el proceso de paz. Bogotá DC: Universidad Externado de Colombia.

Comisión Preparatoria de la Corte Penal Internacional (2002, enero 24). Examen histórico de la evolución en materia de agresión. Recuperado de http://www.corteidh.or.cr/ tablas/r29046.pdf

Congreso de Colombia (2000, julio 24). Ley 599 de 2000. Por la cual se expide el Código Penal. Diario Oficial (44.097). Recuperado de http://www.secretariasenado.gov.co/senado/ basedoc/ley_0599_2000.html 
Congreso de Colombia (2012, julio 31). Acto Legislativo 01 de 2012. Por medio del cual se establecen instrumentos jurídicos de justicia transicional en el marco del artículo 22 de la Constitución Política y se dictan otras disposiciones. Diario Oficial (48.508). Recuperado de http://www.altocomisionadoparalapaz.gov.co/desarrollos-legistlativos-paz/ marco-juridico-para-la-paz/Documentos\%20 compartidos/Acto-Legislativo-N-01-del31-de-julio-de-2012-4.pdf

Congreso de Colombia (2016, julio 7). Acto Legislativo segunda vuelta n. ${ }^{\circ} 01$ de 2016. Por medio del cual se establecen instrumentos jurídicos para facilitar y asegurar la implementación y el desarrollo normativo del acuerdo final para la terminación del conflicto y la construcción de una paz estable y duradera. Diario Oficial (49.927) http:// es.presidencia.gov.co/normativa/normativa/ ACTO\%20LEGISLATIVO\%2001\%20DEL\%20 7\%20DE\%20JULIO\%20DE\%202016.pdf

Congreso de Colombia (2017, abril 4). Acto Legislativo $n .{ }^{\circ} 01$ de 2017. Por medio del cual se crea un título de disposiciones transitorias de la constitución para la terminación del conflicto armado y la construcción de una paz estable y duradera y se dictan otras disposiciones. Diario Oficial (50.196). Recuperado de http://es.presidencia.gov.co/ normativa/normativa/ACTO\%20LEGISLATIVO\%20N%2001\%20DE\%204\%20DE\%20 ABRIL\%20DE\%202017.pdf

Congreso de Colombia (2018, julio 18). Ley 1922 de 2018. Por medio de la cual se adoptan unas reglas de procedimiento para la Jurisdicción Especial para la Paz. Diario Oficial (50.658). Recuperado de http://www. secretariasenado.gov.co/senado/basedoc/ ley_1922_2018.html

Consejo de Seguridad (1994). Resolución 955 de 1994. Establecimiento de un Tribunal Internacional y aprobación del Estatuto del
Tribunal Penal Internacional. Recuperado de https://undocs.org/es/S/RES/955\%20(1994)

Corte Constitucional (2017). Sentencia C-674/17. Reforma a la estructura orgánica del Estado en el marco del proceso para la terminación del conflicto armado en Colombia. Recuperado de http://www.corteconstitucional.gov.co/ relatoria/2017/C-674-17.htm

Corte Constitucional (2018, agosto 15). Sentencia C-80. [MP: Antonio José Lizarazo Ocampo]. Recuperado de http://www.corteconstitucional.gov.co/relatoria/2018/c-080-18.htm

Corte Suprema de Justicia. (2018). Auto No. AP341-2018. [MP Fernando León Bolaños Palacios].

Cruz Rodríguez, E. (2007). Los estudios sobre el paramilitarismo en Colombia. Análisis político, 20(60), 117-134. Recuperado de https:// revistas.unal.edu.co/index.php/anpol/article/ view/46000/47548

Dejusticia (2018). Consideraciones a propósito de la decisión adoptada por la Sala de Definición de Situaciones Jurídicas de la JEP el 7 de mayo de 2018 ante la solicitud de sometimiento voluntario elevada por David Char Navas (Resolución número 000084). Recuperado de https://cdn. dejusticia.org/wp-content/uploads/2018/06/ Consideraciones-Char.pdf

Fiscalía General de la Nación (2018a, abril 9). Declaración del Fiscal General sobre captura de alias Jesús Santrich y otras tres personas. Recuperado de https://www.fiscalia.gov.co/ colombia/fiscal-general-de-la-nacion/declaracion-del-fiscal-general-sobre-captura-dealias-jesus-santrich-y-otras-tres-personas/

Fiscalía General de la Nación (2018b, agosto 23). Comunicado de prensa n. ${ }^{\circ} 32$ - Ley Estatutaria de la JEP. Recuperado de https:// www.fiscalia.gov.co/colombia/wp-content/ uploads/Comunicado-de-Prensa.pdf 
International Centre for Transitional Justice (ICTJ) (s.f.) Tribunal Especial para Sierra Leona [ficha técnica]. Recuperado de https://www. ictj.org/sites/default/files/ICTJ-FactsheetSierraLeona.pdf

Jurisdicción Especial para la Paz (JEP) (2018a, mayo 8). JEP rechaza solicitudes de ex senadores Char y Ashton. Comunicado n..$^{\circ}$. Recuperado de https://www.jep.gov.co/Sala-de-Prensa/ Paginas/JEP-rechaza-solicitudes-de-exsenadores-Char-y-Ashton-.aspx

Jurisdicción Especial para la Paz (JEP) (2018b, agosto 24). La JEP admite y condiciona acceso de dos ex congresistas y un ex agente del DAS. Recuperado de https://www.jep.gov.co/ Sala-de-Prensa/Paginas/La-JEP-admite-ycondiciona-acceso-de-dos-ex-congresistasy-un-ex-agente-del-DAS-.aspx

Oficina del Alto Comisionado para La Paz (OACP). (2016, noviembre 14). Acuerdo final para la terminación del conflicto y la construcción de una paz estable y duradera. Bogotá: OACP. Recuperado de http://www.altocomisionadoparalapaz. gov.co/procesos-y-conversaciones/Documentos\%20compartidos/24-11-2016NuevoAcuerdoFinal.pdf

Redacción Judicial. (2017, octubre 20). Tras su visita a Colombia en septiembre pasado. Los "peros" de la fiscal de la CPI a la Jurisdicción Especial de Paz. Colombia 2020. El Espectador. Recuperado de https://colombia2020. elespectador.com/jep/los-peros-de-la-fiscalde-la-cpi-la-jurisdiccion-especial-de-paz

Semana (2017, febrero 18). Uribistas Buscan pista para aterrizar en Tribunal de Paz. Recuperado de https://www.semana.com/ nacion/articulo/exfuncionarios-uribistas-sepreparan-para-ir-a-la-justicia-transicional/ 515861

Teitel, R. G. (2017). Justicia Transicional (Universidad Externado de Colombia ed.). (M. J. Cleves, Trad.) Oxford University Press.

Tribunal para la Paz (2018a, agosto 21). Auto TP-SA n. 019 de 2018. En el asunto de David Char Navas. JEP. Recuperado de https://www.jep.gov.co/Sala-de-Prensa/ Documents/Auto\%20TP-SA\%2019\%20de\%20 2018\%20-\%20En\%20el\%20asunto\%20de\%20 David\%20Char\%20Navas.pdf

Tribunal para la Paz (2018b, agosto 21). Auto TP-SA n. ${ }^{\circ} 020$ de 2018. JEP. Recuperado de https://www.jep.gov.co/Sala-de-Prensa/Documents/Auto\%20TP-SA\%20020\%20de\%20 2018\%20-\%20En\%20el\%20asunto\%20de\%20 \%C3\%81lvaro\%20Ashton\%20-\%20DEF.pdf

Uprimny, R. (2018, mayo 5). Extradición, víctimas y paz: el caso "Santrich" [columna de opinión]. El Espectador. Recuperado de https://www. elespectador.com/opinion/extradicion-victimas-y-paz-el-caso-santrich-columna-754065 